\title{
Assessment of ELLs' Critical Thinking Using the Holistic Critical Thinking Scoring Rubric
}

\author{
Alexander C. Nanni \\ Mahidol University International College, Salaya, Thailand \\ Philip J. Wilkinson \\ Mahidol University International College, Salaya, Thailand
}

\begin{abstract}
A significant proportion of students entering international colleges in Thailand lack both the English language skills and critical thinking skills necessary for them to succeed in higher education. The ability to think critically has been correlated with successful reading comprehension and grade point average (GPA); however, many high schools in Thailand fail to develop this ability. This paper is part of an ongoing investigation into the use of Facione's Holistic Critical Thinking Scoring Rubric to assess the critical thinking skills of students enrolled in an intensive English program for students entering a Thai university. Students' critical thinking was assessed at the beginning and end of a 10-week term, during which students received explicit instruction on critical thinking. Some students evidenced measurable improvements over the term, and the rubric seems appropriate for future use. As critical thinking has been linked with academic success, this topic is relevant in diverse contexts.
\end{abstract}

More than a decade ago, Pennington (1999) noted that the expansion of educational access in Thailand meant that more Thais were exposed to the "pedagogy of the worksheet" (p. 2). Although numerous reform efforts have been attempted, the Thai educational system remains firmly teacher-centered (Hallinger \& Lee, 2011). Thai students, like all students, have the capacity to learn critical thinking skills; however, the current state of the Thai educational system does not foster the development of these skills. Rote memorization is stressed at the expense of more open dialogue. In this educational atmosphere, critical thinking remains underdeveloped. The lack of critical thinking is detrimental to students in several ways. For example, critical thinking skills have been correlated with academic achievement as measured by grade point average (GPA) as well as with reading comprehension skills (Facione, 1998). Students who hope to enter liberal arts programs at university face an additional challenge. Meaningful interaction among students and between faculty and students is an essential component of liberal arts education (Blaich, Bost, Chan, \& Lynch, 2004), and this interaction requires critical thinking.

This paper documents a preliminary attempt to assess students' critical thinking skills using Facione's (2010, p. 12) Holistic Critical Thinking Scoring Rubric (available at http://www.insightassessment.com/Products/Products-Summary/Rubrics-Rating-Forms-andOther-Tools). This study involved 14 students enrolled in an intensive language class at a Thai 
university which was designed to provide the language skills necessary for success in an English-medium liberal arts program. The students' critical thinking skills, as demonstrated by their participation in structured small-group discussions, were assessed pre- and postintervention using the Holistic Critical Thinking Scoring Rubric. This paper will first review relevant literature on critical thinking, focusing on trends in the assessment of critical thinking. Next, it will outline the methods and results of the pilot study. The paper will conclude with a discussion of the implications for further research in this area.

\section{A Review of Critical Thinking}

Much of the debate over critical thinking has involved different attempts to best define the processes and skills that comprise it (Mulnix, 2012; Petress, 2004). As a result, one of the largest problems in critical thinking research is that this term is not used consistently (Lewis \& Smith, 1993; Petress, 2004). Ennis proposed one of the most cited, and indeed, earliest definitions, stating that "critical thinking is the correct assessing of statements" (1963, p. 20). However even Ennis himself later lamented that this early attempt did not recognize the "creative aspects of critical thinking" and was entirely too "vague" (1993, p. 179). Determining the exact nature of critical thinking is a task that many researchers from a wide swath of specializations have tried to tackle; however, this has just added to the confusion about critical thinking. As Petress (2004) pointed out, psychologists, philosophers, and educators have engaged with this topic; this has led to striking differences in insight and terminology. Similarly, in a study carried out at two American colleges that had been classified as Research I institutions by the Carnegie Foundation, Nicholas and Raider-Roth (2011) found that faculty members "took a robustly disciplinary approach" when defining, teaching, and assessing critical thinking (p. 24). One of the first challenges for this pilot program, then, was to agree on a definition of critical thinking that is not only accurate but which could also be understood by the participants of this study.

This research uses a definition of critical thinking that was agreed upon by a panel of 46 experts on critical thinking from varied disciplines. As Facione (1990) reported, these experts aimed to settle the disagreements by recognizing that critical thinking is "purposeful, self-regulatory judgment which results in interpretation, analysis, evaluation, and inference, as well as explanation of the evidential, conceptual, methodological, criteriological, or contextual considerations upon which that judgment is based" (p. 2). Unfortunately, this definition is far too complex to be understood, in terms of its language, by many English language learners. By focusing on the idea that critical thinking is indeed a process and a learned set of skills, the researchers hoped to give students a less abstract conception of critical thinking. As Mulnix (2012) simply stated, "critical thinking has little to do with what we are thinking, but everything to do with how we think" (italics in original, p. 3). Conceptualizing critical thinking as a series of steps that involve different activities enabled the researchers to provide students with an easily understandable idea of what critical thinking is all about.

\section{Critical Thinking Assessments}

Numerous assessment tools have evolved through the years. Ennis (1999) published an annotated list of available critical thinking assessments and listed over 20 published and available assessments. These assessments can be broadly divided into two categories: those that require students to use recognition memory (e.g., multiple choice or ranking assessments) and those that rely on recall memory (e.g., short-answer, essay, and performance-based assessments) (Butler, 2012). Examples of recognition-style assessments include the California Critical Disposition Inventory and the Cornell Critical Thinking Test, while recall assessments include the ICAT Critical Thinking Essay Examination, the Ennis-Weir Cornell Critical Thinking Essay, and the Watson-Glaser II Critical Thinking Appraisal; furthermore, the Halpern Critical 
Thinking Assessment incorporates both recognition and recall assessment questions. These are only a few examples of commercially published assessments that are often used for research.

As the number of assessments has grown, researchers have begun to look at the popularity and validity of different assessment tools. In Behar-Horenstein and Niu's (2011) review, the most commonly used assessments in research literature were the Watson-Glaser Critical Thinking Appraisal, the California Critical Thinking Skills Test, and the Cornell Critical Thinking Tests. The assessments' popularity was a result of having been "established [by experts for] their reliability and validity" (p. 31), yet the authors' evaluation of the three assessments was inconclusive. In addition to those three most used assessments, Behar-Horenstein and Niu (2011) noted that the most common critical thinking assessment format was multiple choice and that only four of the 42 studies that they reviewed used qualitative methods to assess changes in critical thinking. Nevertheless, Behar-Horenstein and Niu (2011) and Ennis (2008) argued against the efficacy of multiple-choice tests as a means for critical thinking assessment. Recently, researchers have advocated for more open-ended assessment (e.g., essays) and multiple-method assessments that allow students to demonstrate the reasoning behind the stances that they take and that also allow them to demonstrate these skills multiple times over various topics. This serves to reduce the anxiety and washback that result from highstakes testing situations.

\section{Needs Assessment}

This study was conducted after a needs assessment by the two researchers. At the time that the study was conducted, there was no systematic teaching of critical thinking in the intensive language courses. The only related topic that was a formal element of the curriculum was common logical fallacies. Students stand to benefit from additional coverage of critical thinking skills; however, these skills must be taught in a way that complements rather than detracts from language learning. Teaching elements of critical thinking through discussion of reading texts or through emphasis on elements of discussions seems to achieve this aim. The researchers chose to implement supplementary online critical thinking resources because they do not take up class time that could otherwise be devoted to cultivating students' language skills. Ideally, these online resources would allow teachers to make more effective use of the in-class time that they do dedicate to critical thinking.

After evaluating many existing materials, none of which were appropriate for their particular context, the researchers chose to create new materials to be used both collaboratively in the classroom and independently online for teaching critical thinking. Many high-quality materials exist, but the majority of these materials were created to meet the needs of students whose first language is English. Some of these materials were created for university-level students, in which case the content is appropriate but is not accessible to many English language learners because of the difficulty of the vocabulary and the complexity of the grammar. Other materials were created for high school students, in which case the language is accessible but the material does not present a sufficient cognitive challenge. To create appropriate materials, the researchers strove to create materials that were cognitively challenging but that were pitched towards students with an upper-intermediate proficiency in English.

The researchers sought assessment that would align with the first five of the seven purposes mentioned by Ennis (1993): 
Diagnosing the levels of students' critical thinking ... Giving students feedback about their critical thinking prowess ... Motivating students to be better at critical thinking ... Informing teachers about the success of their efforts to teach students to think critically... Doing research about critical thinking instructional questions and issues ... Providing help in deciding whether a student should enter an educational program ... Providing information for holding schools accountable for the critical thinking prowess of their students. (p. 180-181)

The final two purposes were not in line with the spirit of this study because they "typically constitute 'high-stakes' testing" (Ennis, p. 181), meaning that a large value is placed solely on the results obtained from students' scores.

\section{Methods}

This pilot study had two main research goals: (1) to test the effectiveness and appropriateness of online supplementary materials for teaching critical thinking and (2) to evaluate the utility of Facione's (2010) Holistic Critical Thinking Scoring Rubric in assessing critical thinking skills in this specific context. The participants in this study were 14 members of an upper-intermediate level language class. The class met 8 hours per week for 10 weeks. All of the participants were of Thai ethnicity, and their ages ranged from 17 to 20 years old. Eight of the participants were male, and six were female. The study was conducted during one 10-week term in late 2013. Consent was obtained from the participants.

The pilot study adhered to the following procedure. At the beginning of the term, students were placed into small groups (two groups of five and one group of four) for a 20-minute discussion about a controversial topic, in this case about whether graffiti is a form of art. The participants in the discussion were instructed to begin by defining key terms, move on to discuss the topic, and conclude by summarizing the main arguments for and against as well as any conclusions that the group had reached. The group discussion was recorded using a video camera. One of the researchers observed but did not participate in the discussion. After the discussion had concluded, the two researchers watched the video and gave a score using the Holistic Critical Thinking Scoring Rubric.

The students then received an intervention in the form of online resources throughout the term (see Appendix B). Four topics were selected for the online resource materials: intellectual standards, question types, the fundamentals of logical thinking, and common logical fallacies.

Intellectual standards describe characteristics of good critical thinking: clarity, accuracy, precision, relevance, depth, breadth, logic, significance, and fairness (Elder \& Paul, 2008). These standards serve two main functions for the students: to introduce them to critical thinking as a whole and to provide them with clear avenues of improvement.

Question types include opinion, fact, and judgment. In the needs assessment, it became apparent that many students struggle to differentiate between fact and opinion. Furthermore, questions of judgment, in which multiple competing systems must be brought to bear, for example, law and ethics, present an even greater challenge. Without an explicit understanding of the depth of these questions, many students engage with them on a superficial level.

An introduction to logical thinking includes the structure of a logical argument and assumptions. Understanding the fundamentals of logic will strengthen the students' writing and small-group discussions, as well as prepare them for their further studies at the university. 
Finally, studying common logical fallacies_-such as the red herring fallacy, circular reasoning, and argument from authority-will help students to avoid these fallacies in their writing and discussions as well as in their thinking.

Near the end of the term, students participated in another small-group discussion. The same groups were used in order to control for relationships among the students, and the researchers selected media censorship as the topic of the discussion. Again, a teacher observed but did not participate. The discussions were video recorded, and the two researchers independently assessed each student's critical thinking using the Holistic Critical Thinking Scoring Rubric. The rubric has four bands: 1-weak, 2-unacceptable, 3-acceptable, and 4-strong. The rubric is holistic as opposed to analytic, meaning that it does not explicitly assess students in more than one dimension of their performance. That is, students are only given an overall score rather than separate scores in various dimensions. That being said, each band of the rubric includes parallel descriptors. The researchers conducted a norming session in order to test inter-rater reliability. The norming session involved watching two discussion videos independently and assigning a score to each participant. The two researchers then met to compare scores. After identifying the participants about whom the raters had disagreed, they watched the two discussion videos together. Finally, they discussed each participant's performance until they were able to agree on an appropriate score. After completing the norming, the researchers then used the rubric to assess the students in six areas: how well they interpreted facts, how well they addressed counterarguments, how well they considered alternative points of view, how well they provided warranted conclusions, how well they provided justifications for their decisions, and the degree to which they freed themselves from bias. After the independent scoring had been completed, the two researchers compared scores. In the few cases where a student had been given two different scores, the researchers reviewed the videos and rescored the student. By this method, agreement was reached.

\section{Results}

This pilot study produced encouraging results. Of the 14 students, 6 (approximately 43\%) improved by at least one band on the Holistic Critical Thinking Scoring Rubric. The overall average score increased from 1.92 to 2.50 (2 being considered "unacceptable," Facione, 2010, p. 10). While an average score of 2.5 is still not completely in the "acceptable" range, it does represent an improvement over the pre-intervention average score. Before exposure to the online resources, only three students scored above a 2 on the rubric. This can be contrasted with the post-intervention assessment, when seven students scored either a 3 ("acceptable") or 4 ("strong"). Thus, in this case, the rubric proved a reliable measurement tool when used by the two researchers; and the students were assumed, based on their improved scores, to be capable of understanding the different aspects of critical thinking as explained by the rubric. The full results of the pre- and post-intervention assessments are included in Appendix A.

The students indicated that the online materials were appropriate in both language and content. Feedback, both written and oral, was collected from them informally in class by the two researchers. Based on the quality of the in-class discussions, students engaged well with the supplementary materials that they were assigned for homework. The major critique of the supplementary materials was that, although they were suitably paced and suitably challenging, the students found them too dry and thus uninteresting at points. This issue can be dealt with in subsequent iterations of the materials. 


\section{Discussion}

The results of this pilot study seem to indicate that further use of the Holistic Critical Thinking Scoring Rubric would be beneficial. In future terms, expanding the use of the rubric to a greater number of students and teachers will test whether it is truly appropriate for the researchers' particular context.

The moderate improvement in critical thinking skills is also encouraging. Critical thinking is not a skill that can be learned quickly; any gains are to be celebrated. If similar gains can be made over subsequent terms, students will be well prepared for their studies at university.

Time was one of the major limitations that researchers had during this pilot program. As mentioned above, there are only a certain number of hours available for teaching critical thinking skills in the intensive English program. Terms only last for 10 weeks, and the performance assessments in this pilot project were taken after about 6 to 7 weeks. Future studies could provide more time between assessments to allow teachers more time for direct interventions and feedback. Ultimately, further research could investigate how well students are able to perform on the Holistic Critical Thinking Scoring Rubric after two terms (20 weeks).

Another limitation was that the subjects were grouped largely based on their IELTS writing scores. Grouping subjects based on their IELTS speaking scores instead might change the dynamic of the discussion groups. While observing and assessing these discussions, researchers noticed that students with stronger speaking skills might dominate a discussion. At the same time, students with weaker speaking skills might feel intimidated to the point of refusing to interact with the other group members. It was noted that both of these scenarios have the potential to affect the dynamics of a discussion. This is a further area of research in that it is not clear to what extent group dynamics can impact an individual score.

\section{Conclusion}

This paper describes the ongoing integration and assessment of critical thinking at one Thai university. Several students' critical thinking skills increased measurably, and the Holistic Critical Thinking Scoring Rubric proved valuable both as a teaching tool and as a means of assessment. Critical thinking is notoriously difficult to teach, even more so when students have become accustomed to "the pedagogy of the worksheet" (Pennington, 1999, p. 2); however, this difficulty should not discourage educators from trying. The benefits of enhancing students' critical thinking are well documented, and the investment of time and effort towards that goal can pay off. At present, the lack of materials suitable for English language learners hinders the teaching of this subject in certain contexts. This pilot study provides preliminary justification for the educational community to improve this situation by developing high-quality materials for teaching critical thinking to those who need it most.

\section{Author Note}

Alexander C. Nanni, Preparation Center for Languages and Mathematics, Mahidol University International College, Salaya, Nakhon Pathom, Thailand; Philip J. Wilkinson, Preparation Center for Languages and Mathematics, Mahidol University International College, Salaya, Nakhon Pathom, Thailand.

Correspondence concerning this article should be addressed to Alexander Nanni, Preparation Center for Languages and Mathematics, Mahidol University International College, 999 Phuttamonthon 4 Road, Salaya, Nakhon Pathom, Thailand. E-mail: alexander.nan@mahidol.ac.th 


\section{References}

Behar-Horenstein, L. S., \& Niu, L. (2011). Teaching critical thinking skills in higher education: A review of the literature. Journal of College Teaching \& Learning (TLC), $8(2)$. Retrieved from http://www.cluteonline.com/journals/index.php/TLC/article/view/3554

Blaich, C., Bost, A., Chan, E., \& Lynch, R. (2004). Defining liberal arts education. Wabash College Center of Inquiry. Retrieved from http://www.liberalarts.wabash.edu/storage/Defining_Liberal_Education.pdf

Butler, H. A. (2012). Halpern critical thinking assessment predicts real-world outcomes of critical thinking. Applied Cognitive Psychology, 26(5), 721-729. http://dx.doi.org/10.1002/acp.2851

Elder, L., \& Paul, R. (2008). The thinker's guide to intellectual standards: The words that name them and the criteria that define them. Dillon Beach, CA: The Foundation for Critical Thinking.

Ennis, R. H. (1963). Needed: Research in critical thinking. Educational Leadership, 21(1), 17-20.

Ennis, R. H. (1993). Critical thinking assessment. Theory Into Practice, 32(3), 179-186. http://dx.doi.org/10.1080/00405849309543594

Ennis, R. H. (1999). An annotated list of critical thinking tests. Retrieved from http://www.criticalthinking.net/CTTestList1199.html

Ennis, R. H. (2008). Nationwide testing of critical thinking for higher education: Vigilance required. Teaching Philosophy, 31(1), 1-26. http://dx.doi.org/10.5840/teachphil20083111

Facione, P. A. (1990). Critical thinking: A statement of expert consensus for purposes of educational assessment and instruction. Millbrae, CA: The California Academic Press.

Facione, P. A. (1998). Critical thinking: What it is and why it counts. Retrieved from https://spu.edu/depts/health-sciences/grad/documents/CTbyFacione.pdf

Facione, P. (2010). Think critically. Englewood Cliffs, NJ: Prentice Hall Professional Technical Reference.

Hallinger, P., \& Lee, M. (2011). A decade of education reform in Thailand: Broken promise or impossible dream? Cambridge Journal of Education, 41(2), 139-158. http://dx.doi.org/10.1080/0305764X.2011.572868

Lewis, A., \& Smith, D. (1993). Defining higher order thinking. Theory into Practice, 32(3), 131 137. http://dx.doi.org/10.1080/00405849309543588

Mulnix, J. W. (2012). Thinking critically about critical thinking. Educational Philosophy and Theory, 44(5), 464-479. http://dx.doi.org/10.1111/j.1469-5812.2010.00673.x

Nicholas, M., \& Raider-Roth, M. (2011). Approaches used by faculty to assess critical thinkingimplications for general education. Available from http://files.eric.ed.gov/fulltext/ED536592.pdf

Pennington, M. (1999). Asia takes a crash course in educational reform. UNESCO CourierEnglish Edition, 52(7), 17-20.

Petress, K. (2004). Critical thinking: An extended definition. Education, 124(3), 461-466. 
Appendix A

Results of Pre- and Post-Intervention Applications of Holistic Critical Thinking Scoring Rubric

\begin{tabular}{|l|c|c|}
\hline Subject & Pre-Intervention Score & Post-Intervention Score \\
\hline Subject 1 & 1 & 3 \\
\hline Subject 2 & 1 & 3 \\
\hline Subject 3 & 2 & 3 \\
\hline Subject 4 & 1 & 2 \\
\hline Subject 5 & 2 & 2 \\
\hline Subject 6 & 1 & 1 \\
\hline Subject 7 & 2 & 2 \\
\hline Subject 8 & 2 & 2 \\
\hline Subject 9 & 3 & 3 \\
\hline Subject 10 & 1 & 2 \\
\hline Subject 11 & 2 & 2 \\
\hline Subject 12 & 3 & 3 \\
\hline Subject 13 & 2 & 3 \\
\hline Subject 14 & 4 & 4 \\
\hline Average & $\mathbf{1 . 9 3}$ & $\mathbf{2 . 5}$ \\
\hline
\end{tabular}




\section{Appendix B \\ Major Online Teaching Resources Used for Student Intervention}

This appendix contains some of the most useful critical thinking resources that were used in this project. Significantly, these resources use accessible language to explain cognitively challenging material.

\section{Resources from the Critical Thinking Foundation}

The online resources provided by the Critical Thinking Foundation proved invaluable in cultivating students' critical thinking skills. The foundation has published a wide range of highquality materials; the pages below represent only a small sample.

- "Becoming a Critic of Your Thinking": http://www.criticalthinking.org/pages/becominga-critic-of-your-thinking/478

- "Universal Intellectual Standards": http://www.criticalthinking.org/pages/universalintellectual-standards/527

- "Distinguishing Between Inferences and Assumptions": http://www.criticalthinking.org/pages/critical-thinking-distinguishing-betweeninferences-and-assumptions/484

\section{Videos Created for This Project}

The following videos were created by the two authors of this paper. The creators aimed to explain these important critical thinking concepts using language that is accessible to intermediate English language learners.

Intellectual Standards

- Part 1: https://www.youtube.com/watch?v=VelRXwqnrJA

- Part 2: https://www.youtube.com/watch?v=t3QQKE_EGfE

Question Types

- https://www.youtube.com/watch?v=v0SL4AnHuAc

Logical Fallacies

- Part 1: https://www.youtube.com/watch?v=zAuHhLz6zjk

- Part 2: https://www.youtube.com/watch?v=qLTi4f55pK4 